\title{
Estimation of the Duration of Post-partum Amenorrhea among Nepalese Mothers: Some Indirect Techniques
}

\author{
Tika Ram Aryal \\ Central Department of Statistics, Tribhuvan University, Kirtipur, Kathamandu, Nepal \\ e-mail:traryal@gmail.com
}

\begin{abstract}
The main aim of this paper is to use some indirect techniques to estimate the duration of post-partum amenorrhea (PPA) among Nepalese mothers by using the data of Ministry of Health (MOH 2001,2006). The techniques used are based on two types of data, i.e., duration of PPA and breastfeeding (BF). Among the techniques, the one developed by Aryal (2008) provided a very close estimate of the duration of PPA period among Nepalese mothers. The estimated average PPA period was found to be 11.8 months against the observed value of 11.1 months in 2001 data (MOH 2001) while it was 10.3 months against the observed value of 9.3 months in 2006 data (MOH 2006). Estimated PPA period was found to be much close especially by fitting the inverse and logarithmic models. In addition to this, duration of PPA period was also estimated in relation to the characteristics of mothers and the results were found to be consistent with the observed values. It is therefore the used techniques provided very close estimate of PPA period, which might be an applicable technique to estimate the duration of PPA period for any population if the data of the duration of breastfeeding are available.
\end{abstract}

Key words: post-partum amenorrhea, breastfeeding, indirect-technique, curves fitting, fertility

\section{Introduction}

Human fertility related variables like post-partum amenorrhoea (PPA) and breastfeeding (BF) are strongly associated to each other and thereby affect the fertility outcomes (Aryal 2007, 2008). These variables play a crucial role for determining the level of fertility in most of the traditional societies (Aryal 2005, 2006). Since PPA is the period from the end of a woman's pregnancy until the time that she begins to menstruate and it is considered as the temporary infecundable period among women's reproductive life (Aryal 2007a, 2008). It is well-known fact that the natural fertility is influenced most likely by intermediate factors (Aryal 2005a, 2005b, 2007b, 2007c). These factors are included as intercourse, conception, and gestation (Aryal 2007a, 2008, Davis \& Blake 1956). However, conception variable includes PPA period, which is one of the most important proximate determinants of fertility. These proximate factors affect the natural fertility at a greater degree.

A number of previous studies have shown that the distribution of PPA is complex in nature because it may emerge as a unimodal more often than a bimodal and multimodal (Aryal 2007a, 2007b, 2008, Ford \& Kim 1987, Potter \& Kobrin 1981). More specifically it is wellknown fact that fertility is not regulated through the use of family planning methods in most of the society. So the duration of PPA can have much fertility inhibiting effect because a large proportion of a woman's reproductive-life spends in an amenorrheaic state (Aryal 2006, 2007, 2008).

PPA duration among mothers is highly correlated to their duration of $\mathrm{BF}$, and several empirical evidences have also shown that the duration of PPA is strongly associated to the age of mothers and their parity (Aryal 2006, 2007c, 2008, Salway et al. 1993, Yadava \& Jain 1998). It is a well-established fact that educational level among mothers has an inverse association to the duration of PPA(Aryal 2005, 2006, 2007, 2005a, Rahman 1992, Salway et al. 1993, Yadava \& Jain 1998). Previous studies documented that the PPA period varied with the level of socio-economic status of mothers (Aryal 2005c, Brewis \& Regmi 1993). Most of the historical findings have reported the declining trends of amenorrheic period over time (Aryal 2007, 2008, Rahman 1992, Salway et al. 1993). 
Longer duration of breastfeeding corroborates the higher duration of PPA, which leads to the lower level of fertility and thereby to have a better health outcomes among mothers as well as their children (Aryal 2007, 2008). The study on the duration of PPA, and its estimation as well as effect on fertility is most important in a heterogeneous and traditional society. Indeed, not much work has been done yet in Nepal as well as elsewhere to estimate the PPA period by linking the duration of BF. This might perhaps be due to lack of reliable data as well as lack of interest among researchers. Thus this paper attempts to estimate PPA period with the help of the BF data among Nepalese mothers by applying indirect techniques. Different indirect estimation techniques have been discussed to estimate the amenorrheic period, which are based on the relationship of PPA and BF.

\section{Materials and Methods}

This paper utilized the data from Nepal Demographic and Health Surveys (MOH 2001, 2006). In these surveys, besides information on socio-demographic variables, the status of menstruation after delivery, the duration of amenorrhea period and the duration of breastfeeding were collected from all ever-married mothers who had given at least one birth at the survey date. The data from Population Reference Bureau were also used (PRB 1999).

\section{Results and Discussion}

The estimation of PPA period is rather complex in a country with limited data. In such cases, an indirect technique might be one of the most appropriate tools to resolve and tackle the problems (Aryal 2004, 2007, 2008). Indeed, indirect technique has its origin and produces reliable estimate based on the information that is only related to its value indirectly (Aryal 2007, 2008). Basically, estimation of parameters has been worked out using census or vital registration system data. However, in most of the countries, such data do not exist as well as their quality is so poor as a result the estimate based on such data yields inconsistent inferences (Aryal 2004, 2007, 2008). In most of the developing countries, PPA data are omitted and misreported partly due to memory lapse as well as partly due to digit (numeral) preference of the respondents among illiterate mothers (Aryal 2004, 2005a, 2007, Islam 2001). Older respondents are under reporting the PPA events than younger ones (Aryal 2005a, 2006, Cleland 1993). Among other limitations, direct estimation may produce inaccurate estimate of amenorrheic period. Researchers have developed substitute tools to get good estimates from incomplete data because of inaccurate registration of vital events. Researchers have developed techniques in order to get precise, better and reliable estimates of parameters indirectly (Aryal 2007, 2008, Bongaarts \& Potter 1983, Islam \& Islam 1993).

Several researchers have developed indirect estimation techniques by using the PPA and BF data. Most widely used method developed by Bongaarts \& Potter (1983) is used here for the estimation of PPA period among Nepalese mothers. The technique formed the equation of the duration of amenorrhea and an exponent to the quadratic power of BF. For this, the duration of breastfeeding and amenorrhea data were used from twenty-one developed and developing countries. The model they fitted is given below.

$$
\mathrm{PPA}=1.753 \mathrm{e}^{\left(0.1396 \mathrm{BF}-0.001872 \mathrm{BF}^{2}\right)}, \mathrm{R}^{2}=0.96
$$

This equation normally produces a good estimate of the duration of PPA for both developed and developing countries when the data on duration of $\mathrm{BF}$ are available. This equation is universal to compute the duration of PPA because of it high explanatory power $\left(\mathrm{R}^{2}=0.96\right)$. Indeed it fails to provide a good estimate of PPA period using Nepal data (MOH 2001, 2006). Moreover if the same technique is used to estimate the PPA period according to the characteristics of mothers, it also fails to provide consistent estimate of PPA period against to the observed values (Table 1). This suggests us that the equation developed by Bongaarts \& Potter (1983) did not produce good estimate of PPA period for Nepal. This might perhaps be due to different breastfeeding practices among Nepalese mothers.

Islam and Islam (1993) applied the Bongaarts and Potter (1983) equation, which produced underestimates of PPA period among populations of short duration of $\mathrm{BF}$, and overestimate PPA period among the populations of long duration of BF. In a similar manner they developed the following equation using the data of eight countries. The model is given below.

$$
\text { PPA }=3.186 \mathrm{e}^{\left(0.0973 \mathrm{BF}-0.00158 \mathrm{BF}^{2}\right)}, \mathrm{R}^{2}=0.88
$$

This model when applied to Nepal data, it also failed to provide good estimate of PPA. This equation produces overestimates of the PPA duration for Nepal data (see Table 1). Since, both the models failed to provide good estimate of PPA for Nepal data, then we used Islam (2001) equation to estimate the duration PPA. The equation is given below. 
Tika Ram Aryal/Estimation of the Duration.

PPA $=4.5315 \mathrm{e}^{\left(0.019248 \mathrm{~B} \quad \mathrm{~F}+0.0004782 \mathrm{~B} \quad \mathrm{~F}^{2}\right)}, \mathrm{R}^{2}=0.64$

The suitability of this equation using Nepal data provided inconsistent estimates of PPA period. Further the estimated values of the duration of PPA were found to be very far from the observed values for all the characteristics of mothers (Table 1).
All the above discussed models failed to estimate the PPA duration for Nepal data. In this context, Aryal (2008) developed the following model by using the data of the duration of PPA and BF from 47 different developing countries (PRB 1999). The model is given below.

Table 1. Indirect estimation of PPA duration by different techniques

PPA $=1.18563 \mathrm{e}^{\left(0.163792 \mathrm{BF}-0.002859 \mathrm{BF}^{2}\right)}, \mathrm{R}^{2}=0.73$

\begin{tabular}{|c|c|c|c|c|c|c|c|c|c|c|c|c|}
\hline \multirow{3}{*}{$\begin{array}{l}\text { Back ground } \\
\text { characteristics of } \\
\text { mothers }\end{array}$} & \multicolumn{4}{|c|}{ Observed median duration* } & \multicolumn{8}{|c|}{ Estimated duration of PPA (in months) } \\
\hline & \multicolumn{2}{|c|}{$\begin{array}{c}\text { of BF } \\
\text { (in months) }\end{array}$} & \multicolumn{2}{|c|}{$\begin{array}{c}\text { of PPA } \\
\text { (in months) }\end{array}$} & \multicolumn{2}{|c|}{$\begin{array}{l}\text { B \& P } \\
(1983)\end{array}$} & \multicolumn{2}{|c|}{$\begin{array}{c}\text { I \& I } \\
(1993)\end{array}$} & \multicolumn{2}{|c|}{$\begin{array}{l}\text { Islam } \\
(2001)\end{array}$} & \multicolumn{2}{|c|}{ Aryal (2008) } \\
\hline & 2001 & 2006 & 2001 & 2006 & 2001 & 2006 & 2001 & 2006 & 2001 & 2006 & 2001 & 2006 \\
\hline Urban & 32.1 & 36.0 & 4.2 & 8.9 & 22.5 & 23.6 & 14.2 & 13.7 & 13.8 & 16.8 & 12.0 & 10.6 \\
\hline Rural & 32.9 & 34.1 & 11.2 & 9.4 & 22.8 & 23.2 & 14.2 & 14.0 & 14.3 & 15.2 & 11.8 & 11.4 \\
\hline Mountain & 34.2 & 36.0 & 12.3 & 11.2 & 23.2 & 23.6 & 14.0 & 13.7 & 15.3 & 16.8 & 11.3 & 10.6 \\
\hline Hill & 32.8 & 33.6 & 11.4 & 8.6 & 22.8 & 23.1 & 14.2 & 14.1 & 14.3 & 14.8 & 11.8 & 11.5 \\
\hline Tarai & 32.7 & 36.0 & 10.6 & 9.9 & 22.7 & 23.6 & 14.2 & 13.7 & 14.2 & 16.8 & 11.8 & 10.6 \\
\hline Eastern & 32.3 & 30.9 & 9.5 & 8.5 & 22.6 & 21.9 & 14.2 & 14.2 & 13.9 & 13.0 & 11.9 & 12.2 \\
\hline Central & 28.1 & 33.3 & 11.3 & 9.3 & 20.2 & 23.0 & 14.1 & 14.1 & 11.4 & 14.6 & 12.4 & 11.6 \\
\hline Western & 33.9 & 32.7 & 8.7 & 8.2 & 23.2 & 22.7 & 14.0 & 14.2 & 15.1 & 14.2 & 11.4 & 11.8 \\
\hline Mid-western & 33.9 & 34.3 & 13.9 & 10.7 & 23.2 & 23.3 & 14.0 & 14.0 & 15.1 & 15.4 & 11.4 & 11.3 \\
\hline Far-western & 36.0 & 36.0 & 12.1 & 13.2 & 23.6 & 23.6 & 13.7 & 13. & 16.8 & 16.8 & 10.6 & 10.6 \\
\hline Eastern Mountain & 31.1 & 29.6 & 8.3 & 4.4 & 22.0 & 21.2 & 14.2 & 14.2 & 13.1 & 12.2 & 12.2 & 12.3 \\
\hline Central Mountain & 31.9 & 33.4 & 8.9 & 4.4 & 22.4 & 23.0 & 14.2 & 14. & 13.6 & 14.7 & 12.0 & 11.6 \\
\hline Western Mountain & 36.0 & 36.0 & 16.0 & 12.2 & 23.6 & 23.6 & 13.7 & 13.7 & 16.8 & 16.8 & 10.6 & 10.6 \\
\hline Eastern Hill & 29.9 & 31.2 & 10.2 & 4.4 & 21.4 & 22.1 & 14.2 & 14. & 12.4 & 13 & 12.3 & 12.2 \\
\hline Central Hill & 28.2 & 33.3 & 11.2 & 5.2 & 20.3 & 23.0 & 14.1 & 14.1 & 11.4 & 14.6 & 12.4 & 11.6 \\
\hline Western Hill & 34.5 & 36.0 & 8.2 & 8. & 23.3 & 23.6 & 13.9 & 13 & 15.6 & 16.8 & 11.2 & 10.6 \\
\hline Mid-western Hill & 33.0 & 36.0 & 15.4 & 10.7 & 22.9 & 23.6 & 14.1 & 13.7 & 14.4 & 16.8 & 11.7 & 10.6 \\
\hline Far-western Hill & 30.9 & 32.4 & 11.6 & 9.2 & 21.9 & 22.6 & 14. & 14 & 13.0 & 14.0 & 12.2 & 11.9 \\
\hline Eastern Tarai & 32.6 & 30.9 & 9.3 & 9.0 & 22.7 & 21.9 & 14.2 & 14.2 & 14.1 & 13.0 & 11.8 & 12.2 \\
\hline Central Tarai & 26.9 & 29.7 & 11.6 & 10.4 & 19.3 & 21.2 & 13.9 & 14. & 10.7 & 12 & 12.3 & 12.3 \\
\hline Western Tarai & 33.2 & 31.0 & 9.3 & 6.4 & 22.9 & 22.0 & 14. & 14 & 14.5 & 13.0 & 11.7 & 12.2 \\
\hline Mid-western Tarai & 36.0 & 36.0 & 10.6 & 10.5 & 23.6 & 23.6 & 13.7 & 13. & 16.8 & 16.8 & 10.6 & 10.6 \\
\hline Far-western Tarai & 36.0 & 36.0 & 11.6 & 12.2 & 23.6 & 23.6 & 13. & 13 & 16.8 & 16.8 & 10.6 & 10.6 \\
\hline No education & 33.0 & 36.0 & 12.0 & 11.3 & 22.9 & 23.6 & 14.1 & 13.7 & 14.4 & 16.8 & 11.7 & 10.6 \\
\hline Primary level education & 36.0 & 36.0 & 8.8 & 6.5 & 23.6 & 23.6 & 13.7 & 13.7 & 16.8 & 16.8 & 10.6 & 10.6 \\
\hline Secondary level education & 32.3 & 31.9 & 6.0 & 7.6 & 22.6 & 22.4 & 14.2 & 14.2 & 13.9 & 13.6 & 11.9 & 12.0 \\
\hline SLC \& above & 28.1 & 29.3 & 5.5 & 6.7 & 20.2 & 21.0 & 14.1 & 14.2 & 11.4 & 12.0 & 12.4 & 12.4 \\
\hline Quintile groups Lowest & - & 36.0 & - & 13.1 & - & 23.6 & - & 13.7 & - & 16.8 & - & 10.6 \\
\hline Second & - & 36.0 & - & 11.7 & - & 23.6 & - & 13.7 & - & 16.8 & - & 10.6 \\
\hline Middle & - & 29.6 & - & 8.2 & - & 21.2 & - & 14.2 & - & 12.2 & - & 12.3 \\
\hline Fourth & - & 33.9 & - & 5.8 & - & 23.2 & - & 14.0 & - & 15.1 & - & 11.4 \\
\hline Highest & - & 31.4 & - & 8.7 & - & 22.2 & - & 14.2 & - & 13.3 & - & 12.1 \\
\hline Total & 32.8 & 34.3 & 11.1 & 9.3 & 22.8 & 23.3 & 14.2 & 14.0 & 14.3 & 15.4 & 11.8 & 11.3 \\
\hline
\end{tabular}

*Observed values of BF and PPA are taken from MOH (2001, 2006), B\&P=Bongaarts and Potter \& I\&I=Islam \& Islam.

This equation produced an estimate of the duration of PPA of 11.8 months for MOH (2001) and 11.3 months MOH (2006) data, which are close to the observed values of 11.1 months for 2001 and 9.3 months for 2006 data respectively. To some extent, the estimated values of PPA period were found to be close against the reported values for all the characteristics of mothers (Table 1). Thus, all these results indicated that Aryal's (2008) procedure might be an appropriate technique to estimate the duration of PPA if the duration of BF is available from the populations. Further, this technique seems to be applicable for the estimation of the duration of PPA with similar characteristics of mothers in any population of the countries elsewhere.

Indeed the association between PPA and BF is well-established in the literature in most of the societies. We were computed the correlation matrix of PPA and BF by using surveys data (MOH 2001, 2006) in order to see the association of PPA and BF. The results have been presented in Table 2 . 
Table 2. Correlation matrix of the duration of PPA and BF

\begin{tabular}{l|l|l|l|l}
\hline & BF(MOH 2001) & BF(MOH 2006) & PPA(MOH 2001) & PPA(MOH 2006) \\
\hline BF(MOH 2001) & 1 & $.683(* *)$ & .237 & $.458(*)$ \\
BF(MOH 2006) & 1 & $.372\left(^{*}\right)$ & $.564(* *)$ \\
PPA(MOH 2001) & & & 1 & $.562(* *)$ \\
PPA(MOH 2006) & & & & 1 \\
\hline
\end{tabular}

** Correlation is significant at the 0.01 level (2-tailed). * Correlation is significant at the 0.05 level (2-tailed).

The correlation coefficients were found to be highly significant and this indicating that the association between PPA and BF was highly interrelated using $\mathrm{MOH}(2001,2006)$ data of Nepal. It is therefore an attempt to see the functional relations between PPA and BF. The following models have been fitted for the estimation, prediction and graduation of the duration of PPA and BF in relation to the characteristics of mothers (data used from Table 1). The selected models are as follows:

$$
\text { Linear model } \quad: \text { PPA }=\mathrm{b}_{0}+\mathrm{b}_{1} \mathrm{BF}
$$

$$
\begin{array}{ll}
\text { Exponentia 1. model } & : \text { PPA }=b_{0} \mathrm{e}^{b_{1} B F} \\
\text { Growth model } & : P P A=\operatorname{Exp}\left(b_{0}+b_{1} B F\right)
\end{array}
$$

In these models, $b_{0}, b_{1}$ and $b_{2}$ are the coefficients of the models. PPA is the dependent variable, which is measured in months, and BF is the independent variable which is also measured in months. Two survey data were used for fitting the models and the results have been presented in Table 3 .

Table 3. Fitted models including their coefficients and estimated duration of PPA

\begin{tabular}{l|l|l}
\hline Models & Fitted equations & Estimated PPA duration(in month) \\
\hline Linear & $\mathrm{PPA}_{2001}=2.3561+0.2460 * \mathrm{BF}$ & 10.4 \\
Logarithmic & $\mathrm{PPA}_{2006}=-10.8410+.5877 * \mathrm{BF}$ & 9.3 \\
& $\mathrm{PPA}_{2001}=-15.4680+7.4233 * \mathrm{Ln}(\mathrm{BF})$ & 10.0 \\
Inverse & $\mathrm{PPA}_{2006}=58.3450+19.1490 * \mathrm{Ln}(\mathrm{BF})$ & 9.0 \\
& $\mathrm{PPA}_{2001}=17.2010-221.1900 / \mathrm{BF}$ & 10.4 \\
Quadratic & $\mathrm{PPA}_{2006}=27.4837-621.0300 / \mathrm{BF}$ & 10.5 \\
& $\mathrm{PPA}_{2001}=83.4346-4.8789 * \mathrm{BF}+.0804 * \mathrm{BF}^{2}$ & 9.4 \\
Growth & $\mathrm{PPA}_{2006}=157.1790-9.6123 * \mathrm{BF}+.1540 * \mathrm{BF}^{2}$ & 9.9 \\
& $\mathrm{PPA}_{2001}=\operatorname{Exp}\left(1.4700+.0255^{*} \mathrm{BF}\right)$ & 8.7 \\
Exponential & $\mathrm{PPA}_{2006}=\operatorname{Exp}(-.1741+.0690 * \mathrm{BF})$ & 10.0 \\
& $\mathrm{PPA}_{2001}=4.3494 * \operatorname{Exp}(.0255 * \mathrm{BF})$ & 9.0 \\
\hline
\end{tabular}

Observed value of PPA duration for NDHS 2001 data $=11.1$ and NDHS 2006 data $=9.3$

The fitted equations presented in the Table 3 provide the estimated values of PPA duration for both the survey data (MOH 2001, 2006). All the models provided more or less consistent estimates of the duration of PPA. Indeed the inverse and linear models produced much close estimates of PPA duration. These techniques discussed and used in this paper have provided additional idea to estimate the duration of PPA period.
Finally, some remarkable characteristics and results have been observed in the duration of PPA and BF among Nepalese mothers. They are given below:

(i) Among urban mothers, the duration of PPA period was very short in 2001 (4.2 months) as compared to 2006 (8.9 months), which indicated that urban mothers were most likely to practice longer breastfeeding (36 months) in 2006 as compared to 
2001 (32.1 months). Longer duration of PPA among urban mothers in 2006 might perhaps be due to longer duration of $\mathrm{BF}$ practices.

(ii) Longer duration of PPA was observed among mothers who resided in urban areas and better-off regions as well as with those having some formal education over time, which might be the results of the importance of longer BF practices.

(iii) Shorter duration of PPA was observed in 2006 than in 2001 among mothers of Eastern as well as Central hills and mountains over time i.e. ranging 8 to 10 months in 2001 and 4 to 5 months in 2006).

(iv) Duration of PPA was increased over time among educated mothers as well as those who resided in the better-off region, which might be due to awareness on the benefit of longer BF practices to their children.

It is indicative that the $\mathrm{BF}$ practices are universal among Nepalese mothers where the average duration of BF was reported as 32.8 months in 2001 and 34.3 months in 2006. BF practices among mothers were found to be increased over time. Though, the average PPA duration was found to be 11.3 months in 2001 and 9.3 months in 2006. These results showed declining trends in the average duration of PPA period over time among Nepalese mothers. Indeed the result also showed shorter practices of BF over time mostly among educated and urban mothers. It is therefore the duration of PPA period decreased over time.

This paper documents and applies different indirect techniques to estimate the duration of PPA from the information on duration of BF. Two survey data $(\mathrm{MOH}$ 2001, 2006) were used in order to estimate the duration of PPA over time. The techniques used in this paper provided the average duration of PPA to 8 months to 23 months among Nepalese mothers. Indeed, Aryal (2008) technique provided very close estimates of the duration of PPA for the data of Nepal. The estimated duration of PPA was computed as 11.8 months against the observed value of 11.1 months for 2001 while it was computed 11.3 months against the observed value of 9.3 months for 2006. Moreover, the fitted models provided consistent estimates of PPA duration over time among Nepalese mothers. Likewise, the estimated values of PPA duration for all the characteristics of mothers were also found to be very close against the observed values. PPA duration was found to be decreased over time from 11.8 months in 2001 to 9.3 months in 2006. However, PPA duration was found to be increased among mothers of higher duration of BF practices as well as among mothers who resided in urban and better-off region as compared to the mothers who resided in rural and backward region as well as practicing lower duration of BF. The techniques applied in this paper might be applicable to estimate the duration of PPA if the information of $\mathrm{BF}$ is available from the target population. The findings of this paper may help planners and policymakers for designing effective policies and programs for improving the health of women and their children, and thereby meeting the expectation of desired level of fertility in a country.

\section{Acknowledgement}

I would like to acknowledge Professor Kazumi Asako, Hitotsubashi University, Tokyo Japan, for his help and encouragement in preparing this paper.

\section{References}

Aryal, T.R. 2007b. Breast-feeding in Nepal: patterns and determinants. Journal of Nepal Medical Association 46(1), Issue No. 165: 13-19.

Aryal, T.R. 2004. Some indirect techniques to estimate maternal mortality in Nepal. Journal of Population and Social Studies 13(1): 61-76.

Aryal, T.R. 2005. Impact of family planning programs on fertility: alternative methodological perspectives. The Economic Journal of Nepal 28(1):38-44.

Aryal, T.R. 2005a. Testing the suitability of Bongaarts technique in the context of fertility performance in Nepal. Vision of ECOSS 2\&3(2):19-24.

Aryal, T.R. 2005b. Differentials of breastfeeding among rural women of western Nepal: a survival analysis. Journal of Nepal Health Research Council 3(2):58-64.

Aryal, T.R. 2006. Retrospective reporting of the duration of post-partum amenorrhea: a survival analysis. Kathmandu University Medical Journal 4(2), issue 14: 211-217.

Aryal, T.R. 2007. Post-partum amenorrhea among Nepalese mothers. Journal of Population and Social Studies $\mathbf{1 6}$ (1): 33-64.

Aryal, T.R. 2007a. Differentials of post-partum amenorrhea: a survival analysis. Journal of the Nepal Medical Association 46(2), Issue No. 166: 66-73.

Aryal, T.R. 2007c. Age at first marriage in Nepal: differentials and determinants. Journal of Biosocial Science 39, part 5: 693-706. 
Aryal, T.R. 2008. An indirect technique to estimate the duration of post-partum amenorrhea. Nepal Journal of Science and Technology 8: 137-141.

Bongaarts, J. and R.G. Potter. 1983. Fertility, biology and behaviour: Analysis of the proximate determinants of fertility. Academic Press, New York.

Brewis, A.A. and, G. Regmi. 1993. Post-partum amenorrhea: differentials and patterning in a rural Pacific Island population. PSTC working paper series 93-05. Brown University, USA.

Cleland, J. 1993. Fertility trends and differentials. In: Bangladesh fertility survey 1989, secondary analysis. (Eds. Cleland et al.) pp. 8-28.

Davis, K. and J. Blake. 1955. Social structure and fertility: an analytical framework. Economic Development and Cultural Change 4(3):211-35.

Ford, K. and Y. Kim. 1987. Distributions of post-partum amenorrhea: some new evidence. Demography 24:41330.

Islam, M.N. and M.M. Islam. 1993. Biological and behavioral determinants of fertility in Bangladesh: 1975-1989. In: Bangladesh fertility survey 1989, secondary analysis. (Eds. Cleland et al.) pp. 29-72.
Islam, S. 2001. Some demographic models and their applications: particular reference to Bangladesh. $\mathrm{PhD}$ thesis. Banaras Hindu University, India.

MOH. 2001. Nepal demographic and health survey: Report, Ministry of Health, Kathamandu Nepal.

MOH. 2006. Nepal demographic and health survey: Report, Ministry of Health, Kathamandu Nepal.

Potter, R.G. and F. Kobrin. 1981. Distributions of amenorrhea and an ovulation. Population Studies 35:85-94.

PRB. 1999. Breastfeeding patterns in the developing world. Population Reference Bureau, Measure Communication, Washington, DC, USA.

Rahman, M.M. 1992. Measurement of post-partum amenorrhea in Bangladesh. Journal of Biosocial Science 24(1):17-24.

Salway, S., N.C. Roy, M.A. Koenig and J. Cleland. 1993. Levels and trends in post-partum amenorrhea, breastfeeding and birth intervals in Matlab, Bangladesh. Asia Pacific Population Journal 8(2):3-22.

Yadava, K.N.S. and S.K. Jain. 1998. Post-partum amenorrhea in rural eastern Uttar Pradesh, India. Journal of Biosocial Science 30: 227-243. 